ibn Ibrahim ibn Bokhtisho, who probably lived about the second half of the tenth century. (3) "The Memorial of the Oculists," by Ali ibn Isa, a Christian oculist of Baghdad, a contemporary in the ninth century of the famous physician Ibn Sina (Avicenna). Meyerhof fully agrees with Hirschberg when he says that no better ophthalmological text-book was written either in the Orient or the Occident until the beginning of the eighteenth century. (4) "Selection in the Treatment of Eye Diseases," by El-Mausili. This is the first Moslem author among the oculists. He lived at Cairo in the early part of the eleventh century. The only complete copy of this work exists in the library of Taimur Pasha in Cairo. It contains a unique account of a new method of operating on soft cataract by sucking out the soft matter through a hollow needle made of gold or brass.

Enough has been said to indicate the important new material which Meyerhof has brought to light. It is of interest to note that the earlier Arabic science was derived from Greek sources and that its practitioners were Christians.

\title{
AN OPHTHALMIC RADIATION LAMP: WITH A NOTE ON ITS DIAGNOSTIC AND THERAPEUTIC APPLICATIONS
}

THE presentation of this instrument is premature in that its possibilities both in diagnosis and in therapeutics have not yet been thoroughly investigated. Its early notice, however, seems justified if merely to amend a technique in local phototherapy of the eye which I have already described $(1926, a$ and $b$ ) and which I am led to understand is being presently adopted, but which I have now partly abandoned as being inadequate and in some cases potentially dangerous. This technique consisted in localizing the rays from a mercury vapour lamp into a parallel beam by means of a screening apparatus bearing a curved quartz director, and playing them by this means upon the eye. Such a technique is suitable for raying the lids and the conjunctiva, especially in those cases (e.g., trachoma) where the director tip can be inserted into the upper fornix. Incidentally in these, instead of the rod-shaped director originally recommended, an elongated cone-shaped one (K.B.B.) with a broad base tapering to a rounded point at its bent tip will be found more effective. All the rays entering at the base 
are brought to a focus at the tip by internal reflection, and the beam is therefore concentrated here by an amount depending on the ratio of the squares of the radii of the director at these two points. The quartz must be from a good specimen and the base must be optically polished if much of the intensity is not to be lost.

For radiation of the eye, however, such a beam is not susceptible of sufficient control. I have elsewhere elaborated the thesis $(1926, c)$ that an important factor in the aetiology of cataract is the incidence of radiant energy of any wave-length upon the lens. This acts by denaturing its proteins and deranging the autoxidation system upon which the efficiency of its internal metabolism depends, the final process of flocculation of the lens proteins being induced by changes in the concentration of hydrogen ions and salts and osmotic variations, to which in some cases may possibly be added a process of continuous photosensitization. Ultra-violet light, if used experimentally in intensity enough, can cause lenticular opacity. If used in lower concentrations such as do not obviously produce an opacity, it increases the lability of the colloid system of the lens and diminishes its glutathione content, both of which reactions, while they still leave the lens optically clear, predispose to the subsequent incidence of cataract. Some writers on the Continent have stated that with the relatively small intensities of radiation such as are used clinically, applied as they are intermittently, comparatively uncontrolled applications are within the margin of safety. It is to be remembered, however, that many of the eyes subjected to treatment are already diseased, and in these the lens is presumably already predisposed to pathological change; and in any case in the present state of our knowledge the exposure of the lens to any direct radiation seems an unjustifiable risk. With the apparatus figured such a risk can be completely eliminated.

The apparatus is used on the standard Gullstrand slit-lamp table and stand (Zeiss), the slit-lamp and horizontal bracket being lifted off bodily at the point corresponding to $(\mathrm{X})$ in the diagram. The lamp used is a quartz mercury vapour lamp (220 volts, 2-3 amps.) : this is preferable to any type of carbon arc owing to the absence from its spectrum of infra-red, a type of ray peculiarly dangerous to the eye. With this type of lamp at the working distance the heat effect is negligible. The atmospheric type (K.B.B.) is used as it is the most easily manipulated and works over prolonged periods under the most constant conditions. It is enclosed in a casing (C) and is so designed that it occupies the minimum of space, and that the vertical arc is situated in front of a wide slit-aperture (A) which can be rotated in any meridian. The light is concentrated on a diaphragm (D) and brought to a focus by means of a quartz lens 


\section{Ophthalmic Radiation Lamp}

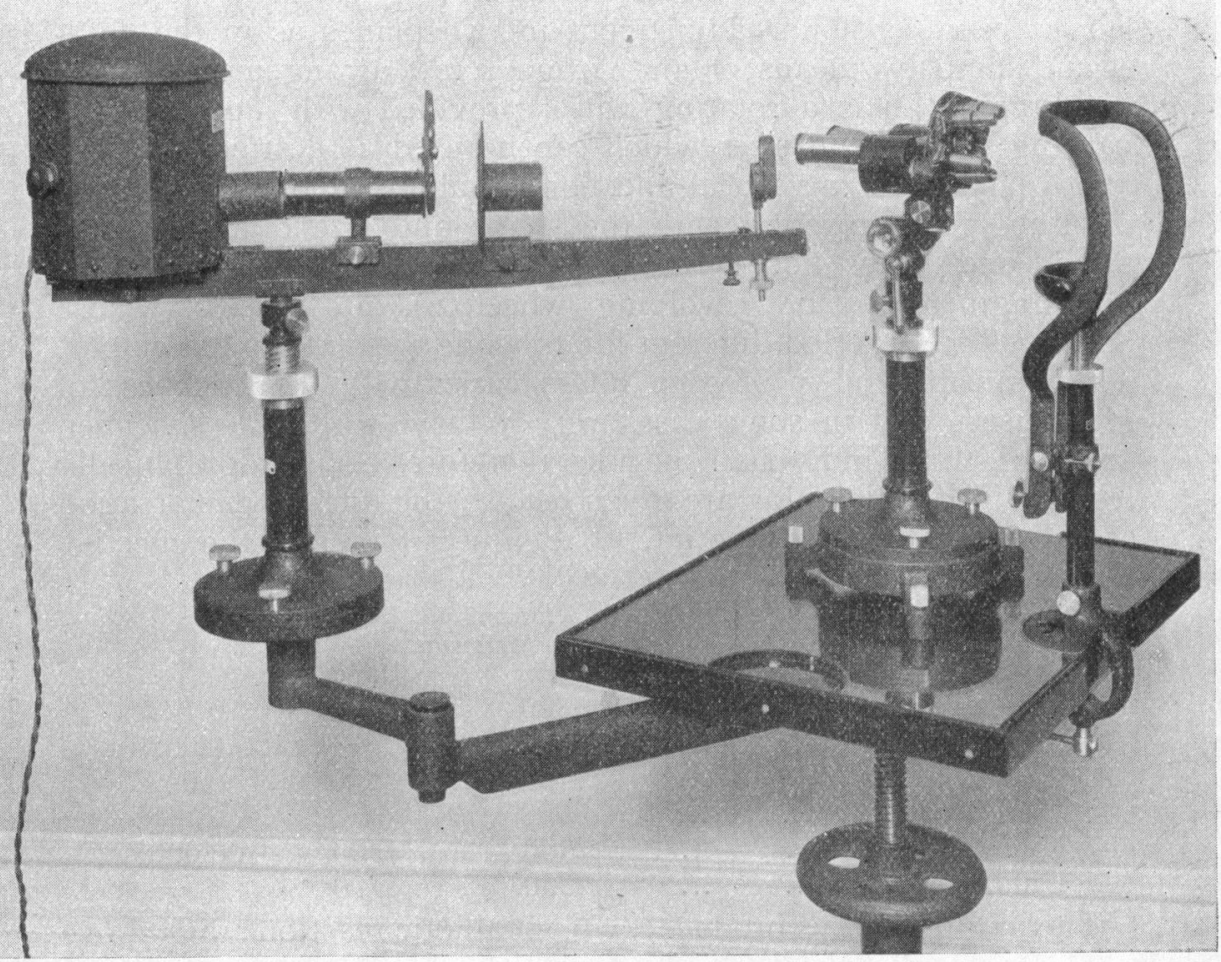

Ophthalmic Radiation Lamp with Spectrum of Arc Used.
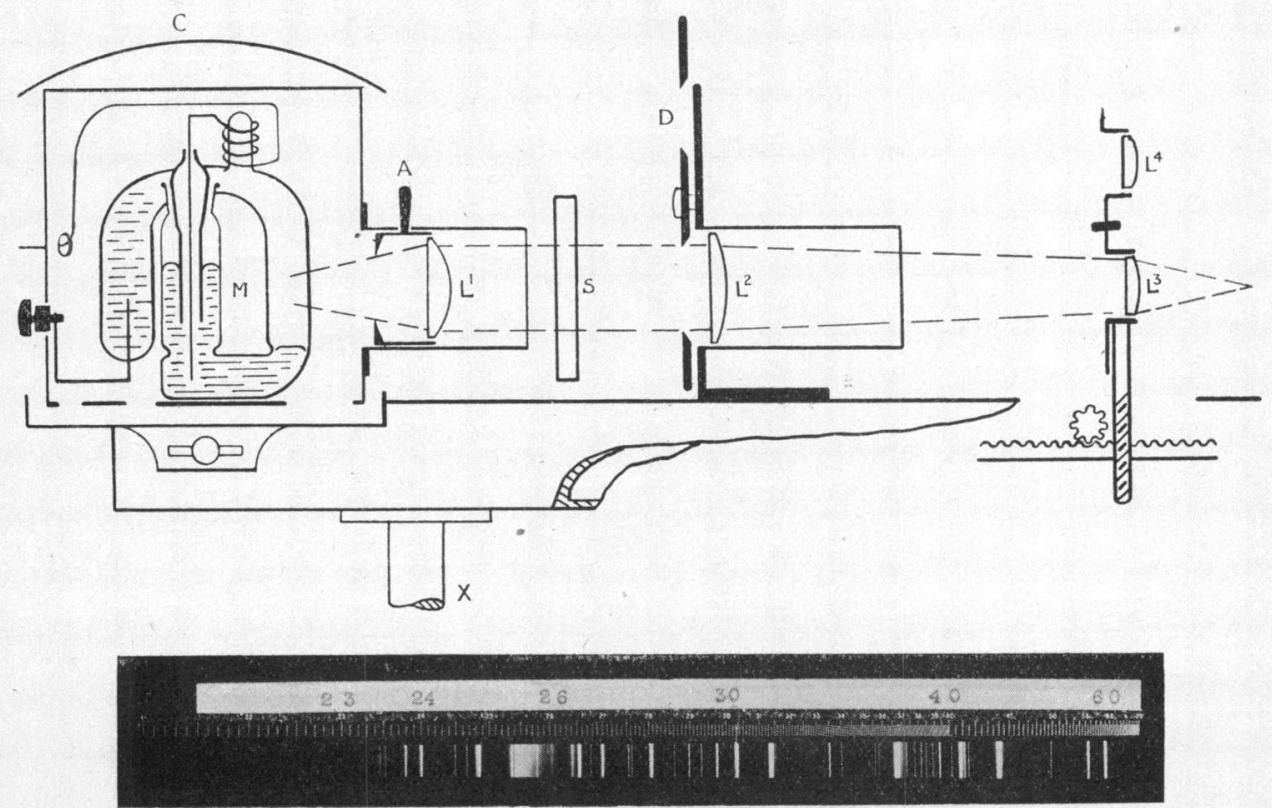
system $\left(L^{1,2,3}\right)$ arranged on the horizontal optical arm. The last lens is capable of fine adjustment in two planes as in the Gullstrand lamp by means of an Arruga screw arrangement. The diaphragm (D) is a rotating wheel provided with apertures of varying shapes and sizes which can be used as desired-a small and a large hole, a vertical and horizontal slit, and two apertures designed to correspond with the shape and size of the everted upper and lower lids. Interposed in the beam is a Koeppe diaphragm tube and revolving wheel (S), into five of whose apertures are inserted different filters while the sixth is left empty. The transmissibility of such filters varies with the thickness of glass used, and in some cases very widely with the specimen supplied. Each individual one must therefore be spectrographically tested. Those I employ are given below : the lines of demarcation are not sharp but exponential. The figures represent the effective limits.

\begin{tabular}{|c|c|c|c|c|}
\hline \multirow[t]{2}{*}{ FILTER } & & \multicolumn{2}{|c|}{$\begin{array}{l}\text { Transmission Limit } \\
\text { in Angström units }\end{array}$} & \multirow{2}{*}{$\begin{array}{l}\text { Thickness } \\
\text { in inches }\end{array}$} \\
\hline & & Lower & Upper & \\
\hline Vogt's red-free filter & $\cdots$ & 3800 & 一 & 0.1230 \\
\hline Crookes' B $\quad \ldots$ & $\ldots$ & 3650 & - & 0.0650 \\
\hline Chance's Ultra-Violet & $\ldots$ & 3150 & 3900 & 0.0670 \\
\hline Vita $\mathrm{C} \quad \ldots \quad \ldots$ & $\ldots$ & 3000 & - & 0.1455 \\
\hline Uviol $\quad \ldots$ & $\ldots$ & 2900 & 4300 & 0.0805 \\
\hline Unfiltered & $\ldots$ & 2350 & 5790 & - \\
\hline
\end{tabular}

The unfiltered rays produce a violent abiotic reaction; rays above $: 900$ (as through the Uviol) a mild one; above 3000 , a very mild one; above 3150 none evident clinically, but having a sedative effect ; above 3700 none at all, but within the limits of fluorescence. The initial dose for abiotic reaction is calibrated by the production of skin erythema (see 1926, b). By changing the filters the range of the spectrum used can be altered at will, and it can be further controlled if desired (for diagnostic purposes) by interposing a second filter between $\mathrm{L}^{2}$ and $\mathrm{L}^{3}$ and by rotating a glass lens $\left(\mathrm{L}^{4}\right)$ into the place of the last lens $\left(\mathrm{L}^{3}\right)$ of the quartz system. The patient's head is steadied by the head-rest and chin-support, and the point of light is observed through the Zeiss Czapski binocular corneal microscope.

Such an apparatus can give a very strong concentration of ultraviolet if necessary, which can be adequately controlled in its therapeutic applications under the microscope so that in no case is there any direct incidence upon the lens. This can be further protected to allow a greater freedom of movement by the preliminary exhibition of eserine to contract the pupil. It can be used with good effect in cases of blepharitis, chronic conjunctivitis, corneal ulcers, recurrent, marginal, and hypopyon ulcers, recent corneal opacities, phlyctenular keratitis, tuberculous keratitis, acne, 
and some cases of episcleritis. I am still of the opinion that local phototherapy is contra-indicated in diseases of the inner eye, with the exception of those cases of iritis showing nodules on the anterior surface of the iris. For chronic cases of iritis, irido-cyclitis, and choroiditis, many of which have otherwise seemed hopelessnot only the tuberculous, but in many cases of infective origintreatment by general light baths is giving results which can certainly be described as eminently satisfactory.

The diagnostic applications of the ultra-violet slit-lamp are at present more of academic than clinical value. R. Thiel of Berlin (1925) has made some interesting observations on this subject; he uses a carbon arc as a source of light, which however requires heavy filtering off of the infra-red and therefore loses much in effective intensity of light. With the slit-lamp described abiotically active light can be completely filtered off by the Crookes' filter, and a red-free picture is obtained. The interest depends largely on the phenomena of fluorescence the effect of which may be intensified, if desired, by giving the patient 2 gms. of sodium fluorescine by the mouth haif an hour before the examination. The skin of the lids fluoresces, and the effect is modified or abolished by slight lesions which are almost imperceptible by ordinary light : this fact can be applied to dermatology generally. The cornea is lit up by a definite fluorescent glow; all details, vessels, nerves, etc., can be sharply intensified in the practically monochromatic light which can be obtained with a combination of filters; pathological lesions, opacities, and folds in Descemet's membrane show no fluorescence but appear as black. New vessels in the cornea appear black, the individual corpuscles can often be distinguished, and the reaction of the capillaries to drugs and other stimuli applied locally can be readily followed. A similar picture is obtained of the iris. The lens fluoresces markedly, and since the absorption of the nucleus and cortex are different, the fluorescence of the various optical layers offers a sharp contrast. Shagreen is well seen, and inflammatory deposits, opacities, and vacuoles and fluid lacunae appear in relief and sharply defined as black or dark blue against the pale yellow-green or lavendergrey of the fluorescent light. A lens dislocated into the anterior chamber or into the vitreous is quite apparent, and can be definitely localized without trouble; an indication of the extent of damage after trauma or needling is given; and the state and extent of the remains of the lenticular substance after extraction can be accurately discerned. The fluorescent light, moreover, can to a large extent be appreciated through a cornea so opaque that it is for practical purposes impermeable to ordinary light, and some idea of the state of the lens can thus be deduced in these cases.

It is hoped in the near future to publish a fuller account of the 
clinical applications of the method and the diagnostic applications of ultra-violet biomicroscopy, when a sufficient amount of clinical material has been gathered to render it of real value. In the meantime it cannot be over-emphasized that, despite the deplorably unfortunate attentions of the lay press, ultra-violet light is not a universal panacea. Further, owing to its equally unfortunate exploitation by practitioners unqualified either in medical or physical training and having no knowledge of the biological action of the potent agent with which they are dealing, it is in many cases being judged by the results which it is only natural to expect. While much positive harm may not usually follow its application in this manner to the skin, the local phototherapist of the eye should certainly be a competent physicist and a competent ophthalmologist, and he should work only with a lamp which runs under constant conditions, and whose individual spectrum is known and whose output of energy intensity as obtained at the point of application has been determined, and on to which are fitted filters each of which has been spectrographically standardized.

The practice of the "treatment" of cataract by ultra-violet light by local application has been carried out in some quarters : those results which have come under my observation might lead me to suggest it as a method for the maturation of cataract. It has been shown that ultra-violet light causes the coagulation of protein which is recognized clinically as lenticular opacity. It is true that in some early cases of acute cataract (diabetic, traumatic) where the process has not yet progressed to the actual coagulation of the proteins of the lens (see 1926,c), transparency may be recovered by the control of the exciting causes; but in all cases an organic opacity once formed is immutable. The coagulation of protein is an irreversible chemical change. It seems not unreasonable to hope that in the future when our knowledge of this change and the factors causing it has been more fully developed it may be possible to prevent its incidence or to delay or arrest its progress, but to set out to "cure" cataract in the sense used above by any means, medical or physical, is quite unjustified.

I am indebted to Messrs. Carl Zeiss Ltd. for their courtesy and to Messrs. Kelvin Bottomley and Baird for the care they have taken in constructing the lamp.

\section{REFERENCES}

Duke-Elder, W. S. $(1926, a)$.-Phototherapy in ophthalmology. Trans. Ophthal. Soc. U.K., Vol. XLVI, p. 213, 1926.

$(1926, b)$. - Observations on the therapeutic action of ultra-violet light upon the eye. Brit. Med.Jl., pp. 891-895, May 29.

(1926, c). - The pathological action of light upon the eye. Lancet, Vol. I ; I. Action on the outer eye, pp. 1137-1141; II. Action on the lens : theory of the genesis of cataract, pp. 1188-1192, 1250-1255.

Thiel, R. (1925). - Ein beitrag zur Spaltlampenmikroskopie des Auges in ultravioletten Licht. Zeitschr. f. Augenheilk., Bd. LVIII, S. 86-91. 